\title{
CURRENT TRENDS IN PERSONNEL TRAINING IN THE UNITED STATES INDUSTRY
}

\author{
Michael Stul', Artem Chaptsov ${ }^{2}$ \\ ${ }^{1}$ Conducive Corporation, Chicago, Illinois, USA, mstulphd@gmail.com, \\ ${ }^{2}$ Ego-Resource, Chelyabinsk, Russian Federation
}

\begin{abstract}
The purpose of this article is to familiarize the audience with the current trends in personnel training in the United States industry. Currently, the personnel training area in the United States is experiencing many challenges. To survive in the new environment, the personnel training field must reinvent itself. The authors reflect on the factors that are either conducive to or have a negative impact on personnel training. The article examines the methods that the personnel training discipline uses to successfully adapt to the new environment. Moreover, the personnel training field helps to shape the industry's employee of the future. The authors also attempt to forecast the impending changes in personnel training by examining the current trends in corporate education. Target audiences for this article include HR Analysts, Training Managers, Vendor Relationship Managers, and business owners who are interested in building and maintaining a modern workforce of productive and committed employees.
\end{abstract}

Keywords: personnel training, corporate education.

\section{Changes to Human Capital in the USA}

To understand the changes that have occurred in the field of personnel training we must first discuss the changes to human capital that occur in the United States industry. Over the past few years, human capital in the United States has changed dramatically, and in a number of ways.

First, consider outsourcing that has been going on for several years now. As a result of outsourcing, the industry's current workforce mostly consists of company employees and contractors, as well as employees and contractors of the third-party solution providers. These team members are recruited for a short period of time, mostly, for the duration of a project and are employed by a variety of organizations. This model of has been described by Gifford Pinchot. (1). Quite frequently, today's employees do not consider themselves a part of a company's long-term development strategy. Rather, they view themselves as participants of a short-term engagement, a "gig". After an engagement is over, the team is disbanded and leaves the company or its members are assigned to other projects. As a result, today's corporate culture is no longer a culture of loyal full-time permanent employees. It is, rather, the culture that is introduced to the client company by the contractors and temporary workforce. It is hard to expect any loyalty from this workforce. Today, the spirit of loyalty is not very common even among permanent fulltime employees. The entire corporate workforce is plagued with anticipation of a new wave of massive layoffs. The notions of loyalty to their employer and pride have become foreign to even the most loyal of employees, who may have worked for a company for decades. Loyalty and pride are gradually replaced with cynicism towards employers. Therefore, company leadership should no longer expect enthusiasm and a desire to work longer hours and on weekends from even from their most loyal associates.

Second, the current workforce is not only disillusioned, but also much discerned and divided. Nowadays, a project team may consist of members who represent many third-party solution providers. This employee division is amplified by employees' remote geographical location and organizational diversity. Outsourcing and globalization merely accelerated these changes in the workforce. Today, it is not unusual for a manager to lead an initiative without actually ever meeting the initiative's participants face-to-face. Quite frequently, these participants reside and work half-way across the globe. A remote workforce, however, is not the most challenging factor. Organizational and cultural diversity, however, may well be that factor. That diversity may be very conducive to achieving outstanding results. By the same token, organizational diversity may be an impeding and stifling factor. In the new environment, a manager and team members might not be employed by the same company. Their employers may have various 


\section{Управление в социально-экономических системах}

levels of organizational maturity and demonstrate a broad range of organizational cultures. Organizational maturity or lack thereof, may, and frequently does, negatively impact both the initiatives' timelines and product quality.

Third, strange as it may sound, company management is no longer accountable for the level of employee competence. Modern industry now has very little visibility into the process of recruiting and training of the workforce in the solution provider companies. A client company purchases a packaged solution rather than the knowledge and skills of individual employees. A company manager has no control over who gets hired into an initiative or how competent that candidate is. Employee competence may vary dramatically across a variety of solution provider companies. And a client manager no longer has a say on how a team members' competence is to be improved should their competence level be less than on par with that of the other team members. As a result, the level of employee competence may be significantly higher among the client company's workforce than the level of employee competence in the provider companies.

Forth, we have to consider the consequences of the recent recession in the economy. During the recession, HR Departments and corporate training organizations in the US have lost their best (and sometimes, overcompensated) full-time permanent employees. And even though the recession is officially over the companies are not demonstrating any propensity to hire their former full-time employees back. During the recession, the industry learned "to do more with less". In other words, they have learned to maintain the pre-recession level of productivity with fewer permanent employees on staff. Maintaining the level of employment at the recession level encourages the industry to reinvent its approach to personnel training. The industry strives to maintain its level of employee productivity by engaging other divisions or third-party companies in performing the key training and development functions. Specifically, corporate training departments rely on other divisions and even the business in the planning and executing of personnel training.

Here is a high-level list of challenges that are currently experienced by the corporate personnel training departments:

- Employee loyalty and personal commitment to their employers has dropped dramatically as compared to those even a few years ago

- Employee competency level is inconsistent across corporate divisions, initiatives, and depends on the standards established by solution providers

- The level of employee career aspirations and professional motivation is inconsistent and more complex than a few years ago. Even on the most complex long-term initiatives, team members are not motivated by a career growth within the client company. The incentive of having access to upward mobility and the traditional career ladder lacks its motivational power. On an initiative staffed with independent contractors and temporary employees, motivating an individual contributor with a perspective of lateral movement is easier than motivating him/her with a opportunity to take their current manager's place in the hierarchy

- Team members are diverse both from a geographical and cultural standpoint. From an organizational standpoint, they may still support the same initiatives and report into the same leadership, but they might not be employed by the same company. Each one of their employers has its own culture, maturity level, level of required competency and so on.

- Employees in the training departments have to rely on other divisions and even their business clients in the planning and execution of the training activities and initiatives. The training processes change to accommodate the influx of non-training professionals into the personnel training field.

\section{Human Capital Development Trends in Corporate Education and Training}

The current corporate education and training practices are shaped by the new challenges in the field of human capital development. Currently, three key groups of changes to these practices are the most prominent. These changes occur in:

- The roles and responsibilities of the training professionals and the students.

- The approach to personnel training.

- The use of Organizational Change Management methods in personnel training.

Let's review each one of these changes separately. 


\section{Changes to the roles and responsibilities of the training professionals and the students}

Over the past 15-20 years, the roles and responsibilities of the training professional and the student have changed at least thrice. These changes can be loosely grouped into three time periods.

Period 1: before 2010 .

This period is characterized by a clear separation of the responsibilities and accountability of the students and the training professionals. During that period, the training professionals have been accountable for the development of instructional content whereas the students have traditionally been considered merely as consumers of such content. The role of the students has been somewhat limited because no one has expected them to either create the training content or participate in the training of other employees or solution providers. This separation of duties has influenced the approach to the hiring of the training professionals. Companies have actively hired instructional designers, instructors, and training administrators who have demonstrated an expertise in a specific business area. An instructional designer or an instructor has been responsible for the development of the training materials, be that a training manual, a job aid, or an exercise guide. That training specialist had to have a background in a specific professional field aligned with the training goals of a particular industry. In other words, banks have actively recruited the training professionals with a background and experience in the banking industry and a specific area in finance. An additional background in the training field, such as adult learning and development, instructional design, educational administration was considered a definite advantage, but was not mandatory. An ideal training candidate for the banking industry, for example, had to have an undergraduate degree and experience in finance and a graduate degree in adult education. In short, during that period, training professionals were responsible for the development of the training materials and delivering the training content and the students were merely responsible for passively consuming that content.

Period 2: 2010-2014

During that period, for a variety of business reasons, the industry has actively embarked on the new distance learning and remote training methods, such as Computer - Communicative Collaborative Education (CCCE). Whenever CCCE method is used, the training professional is primarily responsible for facilitation and delivery of the instruction. That training professional can play the role of a ComputerBased Training (CBT) developer, educational quality assurance specialist, Learning Management System administrator, or content moderator. The training professional, however, was no longer accountable for possessing an expertise in a specific field of the business.

The role of a student has also changed. The CCCE method entails a student's active involvement in the development of an instructional content as both a Subject Matter Expert (SME) and content developer. As a SME, the student must have an expertise in a specific business area. As a content developer, the student creates the training plans, instructional courses, instructor and student guides, job aids and reference materials. The extent of the student's involvement in the development of the instructional materials varies depending on an industry and a company's specific needs. Some companies are more aggressive in getting the students engaged in content development; other companies only charge the students with providing their expertise as a SME. Yet some companies went even farther and put some students in charge of training others, that is, facilitating instructional activities.

With the roles of instructors and students actively changing, new roles and responsibilities emerge. The training departments have assumed new responsibilities. In the new training departments, an associates' role is rather that of an editor of the training content than of the creator of that content. These associates have their core expertise in learning methodologies. Their expertise allows them to efficiently organize instructional content created by a SME to shape that content into an instructional course. Professional training specialists are no longer expected to be experts in any business field other than the adult learning field. More often than not their role in the new environment is administrative. They manage the learning process rather than create instructional deliverables. During that time period, the training departments have created new positions, such as training development managers, quality control analysts, and teleconference moderators. Training development managers analyzed the current stakeholder learning needs, wrote business and functional requirements for instructional courses, and developed training strategy documents. All these documents were used by instructional designers and developers to create training programs, curricula, and instructional content. Quality assurance analysts examined the training courses to ensure their quality and compliance with company standards, governance, and branding policies. Also, these specialists ensured that the format of the training courses met 


\section{Управление в социально-экономических системах}

the standards of the learning management systems and the platforms that supported remote instruction and distance learning practices.

Teleconference moderators assisted instructors in class facilitation when instructors were using remote learning technologies. Their assistance allowed instructors to focus on delivering the learning content and facilitating instructional activities rather than on the technologies which could be advanced and fairly complex.

Period 3: the current stage. It has started around 2013-2014.

Starting 2013-2014, the student's role in personnel training has increased exponentially. The students are now more actively involved in both development and delivery of instructional content. To an observer, it looks as if students are trained in a side job as adult learning professionals. In that position, the students actively create instructional content and teach others. An associate in the training department, however, is no longer charged with either of these responsibilities. Corporate training departments assume new responsibilities as providers of contract administrators, training logistics specialists, and mentors. As contract administrators, training associates negotiate contract terms with the suppliers of instructional technologies and equipment. Their role also extends to managing agreements with the business and affiliates. These agreements cover the terms of training services coordinated by training departments. In some cases, these agreements may include the terms of using employees provided by the business as creators of instructional content and instructors. These responsibilities are relatively new for training departments, but they do impact whom the training departments recruit and hire as employees. In the new environment, a training manager has to have an expertise in contract management, vendor management, market analysis, engagement management, and be comfortable managing providers rather than internal company resources. On the other hand, training departments are accountable for coaching internal resources in their roles as creators of the training content and instructors.

Introduction of the changes to the roles and accountabilities of the training professionals and students is a current trend in corporate personnel training. Over the last 15-20 years, the roles of a professional training specialist and a student have changed drastically. Training specialists have relinquished their responsibilities as active developers of instructional content and instructors and assumed more administrative roles. The student's role in the instructional process, on the other hand, has morphed into an active role of a planner, designer, developer, and deliverer of instructional content.

\section{Changes in the approach to personnel training}

During the same time periods the industry has actively evaluated its approach to the methods of instruction. Some 15 years ago, classroom instruction or Instructor-Led Training (ILT) has been the most common instructional method. That method entailed a training professional conducting a class face-toface with the student audience. The audience had to be physically present in the same location as the instructor who personally facilitated all learning activities. This approach, though the most prevalent at the time, had some obvious disadvantages from a learning efficiency and economic viability standpoint. First, that method assumed all learning activities being identical for all employees in a similar role. The method did not support a differentiated approach to employee training based on the specifics of their organization, its geographic location, or regional culture.

Second, the students' role in the learning process was predominantly passive. This approach only entailed a student being a consumer of the knowledge provided by an instructor. The use of ComputerBased Training (CBT) did not have a profound impact on the traditional breakdown in the training participants' responsibilities. The CBT method has been used as one of the means of classroom instruction. Even the requirement to interact with a computer program while taking a course or a test did not make this approach anything more than passive on the students' part.

Third, from a financial standpoint, this method was not the most efficient. More often than not students had to travel to participate in the training. The industry was on the hook to cover their travel expenses. The CBT approach did not contribute much in terms of improving economic viability of the training. Development expenses associated with the CBT tend to run high. Once again, the industry was on the hook either for covering production expenses for the CBT developed in house or for the licensing cost if a CBT course was created by a solution provider.

The Computer - Communicative Collaborative Education (CCCE) method of instruction relied heavily on virtual instructor-led classroom training (VILT). This approach allows for conducting em- 
ployee training across the globe using a virtual classroom. At first glance, this approach looks merely as enhanced classroom training. This is, however, not so simple. VILT and CCCE in general change the standards of instruction dramatically. A traditional instructional approach only entails passive consumption of an instructional content by a student audience. CCCE is not feasible without getting employees actively involved in creating an instructional content. We are not just talking active teaching as in facilitating learning activities by an instructor. CCCE implies that employees will act as creators of instructional content and teach others. Employees are expected to find solutions to some of the business challenges based on their professional experience and actively share that information with other training participants. The virtual classroom method does not put any limitations on employee locations. A class can be attended by employees working in company offices across the globe. A consideration for employee cultural background and local experience and diversity in resolving complex business challenges becomes paramount for the success of the training. The CCCE method of personnel training is every bit as structured as the traditional Instructor-Led and CBT methods. Its success, however, requires a shift in attention to the role and experience of an individual employee, their cultural background, experience, and learning preferences. One of the disadvantages of CCCE and VILT in particular is that these methods of instruction rely on a group of employees generating new knowledge and skills in a structured and controlled environment. Once again, this instruction is formal and managed and evaluated in terms of how uniform the resulting knowledge is. With the use of these centralized methods, an opportunity to tap into an individual employee is somewhat limited.

The current approach to instructional methods is dramatically different. A modern approach to instruction and its efficiency is focusing on an individual employee and their uniqueness. This approach favors more informal methods of employee training over the formal ones. A large group learning setting and CBT are replaced with an approach requiring a very small group or face-to-face engagements. Formal and centralized facilitation of learning activities are replaced with informal decentralized learning methods using non-traditional venues, such as social networks and a peer-to-peer knowledge transfer. From a targeted audience standpoint, the current approach stands for individual, not group training, very personalized in nature and paying a maximum attention to the specifics of an employee's job and its cultural component. That cultural component entails not just an organizational, division, department or group culture, but ethnic, geographical, racial, business, and personal cultural specifics of an individual team member as well. This method assumes that an instructor as a source of the ultimate wisdom is replaced with a distributed network. Each network member acts as a change agent interacting with the target audience in a very informal and unstructured way via a variety of training and communication venues. This education is decentralized and very flexible to make the learning process pleasant and convenient for each individual employee. The industry's decision to transition to this distributed model of training was well received by the current workforce a part of which is comprised of the Millennials. For this audience, self-study and cross-training via social networks is more natural than for the older employees. This approach contributes to training efficiency and personal commitment to education.

Table 1 summarizes the changes in the approach to personnel training.

Table 1

Trends in the approach to personnel training

\begin{tabular}{|c|c|}
\hline Trend Title & Trend Description \\
\hline Active use of self-study & $\begin{array}{l}\text { - Subject Matter Experts (SME) create and deliver instructional mate- } \\
\text { rials in a partnership with training professionals } \\
\text { - Instructional materials are published on the Intranet, on SharePoint, } \\
\text { Microsoft OneDrive and Learning Management Systems (LMS) } \\
\text { - Students may take the training at their convenience } \\
\text { - Face-to-face personalized training is as available as group training }\end{array}$ \\
\hline $\begin{array}{l}\text { The use of virtual venues } \\
\text { and supporting tools }\end{array}$ & $\begin{array}{l}\text { - Limited need to travel to a specific country or location to take the } \\
\text { training. The training is performed remotely. } \\
\text { - Broader use of Virtual Instructor-Led (VILT) instruction } \\
\text { - Extensive use of virtual training technologies, such as virtual cloud } \\
\text { labs SkyTap, HP Virtual Lab, platforms Lifestream, Microsoft's vir- } \\
\text { tual reality glasses Hololens (future) }\end{array}$ \\
\hline
\end{tabular}




\section{Управление в социально-экономических системах}

Table 1 (end)

\begin{tabular}{|c|c|}
\hline Trend Title & Trend Description \\
\hline $\begin{array}{l}\text { Changes in the training delivery } \\
\text { methods }\end{array}$ & $\begin{array}{l}\text { - Broad use of venues that employees use at home, in the workplace, } \\
\text { and at school (e.g., social and professional networks) } \\
\text { - Broad use of corporate social networks (e.g., Yammer). Creating } \\
\text { corporate networks that mimic social networks } \\
\text { - Use of YouTube to distribute instructional content (dedicated paid } \\
\text { channels that are available to employees by subscription and meet all } \\
\text { corporate security requirements) }\end{array}$ \\
\hline
\end{tabular}

\section{The adoption of Organizational Change Management methods in personnel training}

The use of venues that are typically employed by Organizational Change Management in corporate education is another trend in personnel training. Organizational Change Management (OCM) is most commonly defined as a coordinated practice to ensure the effective transition of individuals, teams and organizations from the current state to a desired future state. It ensures a solution that is applied to support the new state is embraced, adopted, and used proficiently. In the US industry, Organizational Change Management is a separate discipline. In some countries, the function of a successful adoption of a change is one of the functions of Project Management. In the United States, Project Management only ensures the solution is designed, developed and delivered successfully. Unlike Project Management, OCM focuses on ensuring the adoption of a solution and overcoming employee resistance. OCM Managers partner up with Project Managers, company Leadership, division heads, HR departments, Corporate Communications groups, and training organizations. OCM employs the current research in human behavior to ensure efficiency of its methods. These methods include a broad use of social networking, creating and maintaining change networks to support employee activities during and after the initiatives, and active engagement of Change Champions. Other OCM methods include targeted messaging, use of dedicated SharePoint sites, presentations and other engagements. These methods are very efficient in ensuring employees are aware of the upcoming changes and are adequately prepared for them. No wonder the training organizations actively use the methods employed by OCM. The question, however, is, why do the OCM methods have become so popular now to such an extent that we can talk about the use of OCM methods in corporate training as a current trend?

The use of OCM methods in personnel training is precipitated by an unfortunate change in employee attitude toward education and talent management, corporate mobility, and personal and professional development in general. In recent years, this attitude has deteriorated from positive to negative, or, at the very least, indifferent. To discuss the change in employee attitudes, let us first review some of the most typical scenarios that entail employee education in the United States industry.

First, in the United States, the training traditionally exists in the form of continued education which is a part of career management. In the United States industry, continued education is an employee's responsibility. For each individual employee, learning programs are created. The purpose of these programs is to support an employee's professional development and personal growth. As a rule, these programs are built based on a feedback from an employee, their manager's recommendations, and the company need for experts in a particular field. Semi-annual and annual employee evaluations incorporate an evaluation of employee successes in professional development.

Second, employee training is also a requirement emposed by Federal and State regulations and rules, as well as the rules emposed by a specific company or a professional association. The purpose of these training programs is to ensure an employee is fit to continue employment with a company or perform certain duties. Examples of such training include a variety of compliance courses, such as "professional ethics", "secure use of computer networks", "your responsibilities as a company employee", and "quality system overview". Frequently, the goal of such training is to obtain a professional certificate or a license.

Third, a need for the training may result from system, process, or organizational changes. When changes occur, employees must learn to master a new system or process. These changes routinely occur in the industry, regardless of a company's size. Occasionally, however, these changes occur on a broader, company-wide scale as a result of strategic changes in the market or in the company, such as mergers 
and acquisitions, outsourcing, or change in company leadership. Most of these changes inevitably lead to a change in organizational structure and employee duties and accountability.

Traditionally, the first two training scenarios have associated with a positive employee attitude and have remained very popular among employees. Even the third scenario has had a support among employees, especially when the training has been adequately managed. Several factors have contributed to this popularity. The key factor in popularity of the training has been a traditional understanding of a career growth in the industry. In the past, employees realized that a successful career is rooted in personal productivity. The training was necessary to improve the knowledge and skills that resulted in higher productivity. Employees saw a value proposition in the training as, in their eyes, the training associated with higher productivity in any of these three scenarios, and therefore, to continued employment and/or a promotion. This attitude has determined low resistance to the training among employees. Lately, however, employee attitude toward training has started to change. Why is this happening now?

First, in a current organization, a team consists of employees with diverse and complex career preferences and aspirations. Currently, the industry heavily relies on freelancers, contractors, and offshore resources. Most of these resources are hired only for the duration of a project and leave the company upon completion of a project. In this environment, for most employee, learning new technologies, improving productivity, and mastering new processes is a moot point. Why invest any time and effort in the training if the training and personal productivity is not a guarantee of their employment on the next project?

Second, with outsourcing, the training is now somewhat of an evil buzzword. In the mind of many employees, the training equates to a requirement for higher productivity with no added pay or to a layoff. So, what is the point of mastering a new skill in the current workplace when you are likely to be let go in the next wave of layoffs? Your survival in the company no longer depends on your "value" to the current employer or your skillset.

A complexity and diversity of career aspirations is one of the factors that contribute to a negative attitude toward the training among employees, but not the only one. There are some other factors that contribute to a negative attitude toward the training. These factors include:

- A lack of employee understanding of organizational changes. As a rule, employee attitude toward any change is negative or indifferent by default. Organizational changes frequently result in higher levels of stress among employees, higher turnover rates, and medical and psychological issues. When a company is in distress, training and education are among the lowest employee priorities.

- Management's negative attitude toward the training. This attitude is a result of the hiring practices that have changed since the nineties. Companies tend to scrutinize the training budgets and are no longer willing to cover employee education or invest in personnel development. In the eyes of a manager, the training is an activity that gets in the way of meeting the goals.

- Globalization and outsourcing. As part of employee layoffs, employees are frequently asked to train their replacements to whom their jobs are outsourced.

A negative attitude toward the training is a result of the changing economic and employment conditions and lead to a higher employee resistance rate. The resistance can be both passive and active. Passive resistance is manifested in a lower degree of behavioral change. In other words, employees may complete the training, but the training does not lead to any changes in their behavior. For example, it does not lead to higher productivity. Active resistance can take the shape of skipping classes under the pretense of having higher priorities at work. A negative attitude toward the training among employees leads to a higher level of employee resistance. Employee resistance negatively impacts the training attitudes and results. That is a "catch 22 " situation.

Employee resistance to personnel training is a systematic factor that must be considered by corporate training departments. This factor, however, is not sufficiently studied in the industry or addressed by training practitioners. The practitioners frequently think that employee resistance to the training can be addressed by making education more efficient or simply more attractive. Unfortunately, training efficiency may remain low even if the training is well-organized, well-facilitated, or very interactive. Without addressing the factors that increase employee resistance to the training not even the most efficient approach can improve the training outcomes. This is the reason corporate training departments adopt the Organizational Change Management (OCM) approaches to changing employee beha- 


\section{Управление в социально-экономических системах}

viors. The approaches help to lower employee resistance to a change. Which OCM methods prove to be the most efficient in addressing employee resistance to the training?

First, the training departments and project managers must secure support by Executive and Senior Management. Executive and Senior Management must understand and support the importance of the training and help to promote it among a company's middle management. This support translates into a better support of the training by the managers who make decisions about their direct reports' workload. In a company that supports OCM approach to managing employee behavior, Executive and Senior Management make it clear that the middle management is accountable for promoting the importance of professional development among their direct reports. This approach helps to address the issue of employee availability to take the training. The training is simply given the appropriate priority on an employee's "to-do list".

Second, the importance of the training must be evaluated in the context of OCM activities. A relationship between OCM and the training is symbiotic. Typically, OCM activities are employed when a change occurs. On the one hand, the training is an important part of promoting a change because it improves employee confidence when embarking on a new solution. On the other hand, a successful outcome of the training depends on employee understanding and acceptance of a change and its importance. That is exactly what OCM helps to promote. Employee understanding and acceptance of a change is supported and reinforced by a variety of OCM interventions. These interventions may include a timely and proactive employee notification of an upcoming change, explaining the meaning of the change to employees, and demonstrating advantages of the change to all stakeholders impacted by the change. The purpose of this approach is to reduce and eliminate employee anxiety and resistance to change and to ensure employees' passionate support of the change. Building knowledge and skills is an important element of making employees feel passionate about a change. The better employee understanding of what exactly is changing in their lives and work, the less anxious and condescending they will feel about a change. On the other hand, the absence of resistance translates into better training results and a positive behavioral change.

Third, a successful training promotes active employee participation in a change. From that standpoint, OCM and the training are very much alike. The OCM also employs the methods for engaging employees. For example, these methods entail a deployment of Change Networks. A Change Network is a network of the most influential employees and Subject Matter Experts (SME) that is used to assist with the rollout of a change. These influential employees and SME are frequently called Change Champions which means, facilitators of change. Corporate Change Networks are akin to social networks and serve the same purpose of providing support during a change. In a Change Network, a flow of information is facilitated from within an organization, such as a Division or Department. A successful Change Network is another example of a partnering relationship between the training and OCM. The training is used to prepare Change Champions for their role as change facilitators. On the other hand, properly trained Change Champions play a critical role in disseminating knowledge. In a time of change, these influential employees and SME may be more efficient as sources of information and knowledge than formal trainers. That occurs because employees may perceive professional educators as outsiders and therefore be more resistant to change and less susceptible to consuming the new information. Once again, OCM and the training form a partnership that allows for addressing employee resistance to make the training more efficient. The training uses the methods employed by OCM. OCM relies on the training to help with the execution of some of its strategies. Both OCM and the training share a common goal to change employee behavior and make personnel better prepared for a change.

The methods that entail a partnership between OCM and the training are just a few available approaches that are used to reduce employee resistance. Both the training and OCM share an understanding that, as a rule, better-informed employees are more successful at the training. The positive training results can be achieved by employing the OCM approaches to reduce employee resistance and therefore improve adoption of new information.

What does the near future of personnel training hold?

We argue that we can forecast the future trends in personnel training by analyzing the current trends. The forecasted trends in personnel training are as follows.

\section{Solution-driven personnel training}

The training as an instrument of professional growth and career aspirations may eventually become the thing of the past. The latest victim of the race to save money and show better-then-expected annual 
results, personnel training will become less of a bonus. On the other hand, it will rapidly become a part of the overall corporate development strategy. In the modern industry, strategic objectives, such as increased profitability, improved time to market, and a positive user experience include a learning component. Corporate initiatives that do not have a documented personnel training approach will have less of a chance to be approved by the Leadership. Corporate officers from a project manager to Senior Management will have to have a clear understanding of the personnel training component if they want an initiative to be successful. In other words, the training will more often than not be created as a situational solution to a challenge. The training that entails personnel development to improve the value of human capital and motivate employees to invest in their professional growth may become less prevalent.

Increased value of cross-training within a team

The value of fundamental training will decrease. It is obvious now that the industry is geared toward shorter, more contained initiatives. These tend to be less costly, more manageable. The personnel training model that favors a rapid knowledge transfer fits the said mode better than a long-term talent development. This approach precipitates the increased value of cross-training among team members. This training is by no means formal, yet it is a quick and dirty way to pick up the skills that allow a project to continue. The value of such training methods as on-the-job training, mentoring, coaching, and "shadowing" the actions of another employee will rapidly increase. In our culture, we already observe this trend in the video gaming industry where the members of a gamer network learn from each other. In corporate environment, this model will become more and more instrumental. This trend will become more pronounced with further development of the current "social/corporate networking" practices. Today, the US industry is still heavily dependent on the training department as a single source of truth in knowledge distribution. In the near future, however, a distributed network of employees will facilitate employee interaction to acquire the new knowledge and skills. This trend will likely impact the current hiring practices, too. In the future, hiring will favor candidates who can efficiently coach other team members to improve their productivity rather than just plan, develop, and perform the training.

Increased demand for refresher training

Traditionally, in the USA, personnel training have served for helping employees to adapt to new challenges. In the past, the depth of knowledge was critical to resolving complex challenges. Nowadays, however, the depth and breadth of knowledge and skills are not as critical to the industry as the rate with which that knowledge refreshes. The timing of a planned obsolescence for the existing intellectual capital has shortened dramatically. The speed, with which the new knowledge is generated, on the contrary, has increased. The skills that are important today may become quite useless tomorrow. The current vast archive of the existing knowledge and skills in the form of training artifacts will become obsolete in the near future. The existing learning methods will become useless in helping employees to address the upcoming challenges. In the future, the training departments will be focusing less on improving the ways to deliver the knowledge and more on managing the rate of knowledge replenishment itself. Having the ability to facilitate employee refresher training frequently and painlessly will become critical for a success in the industry. From that standpoint, advanced methods of increasing efficiency of systematic, cyclical employee refresher training will gain value and compete against each other in the current employee training marketplace. It is conceivable that this change will likely impact the Learning Management Systems architecture and the technologies for delivering the training content.

Training regionalization and decentralization

In the current US industry, the training planning and facilitation remain very centralized processes. More often than not the training is orchestrated from a corporate headquarters and uses standardized templates, processes, and technologies. The industry, however, is warming up to the value of adapting the training to the need of a specific student or group. Many companies now realize the value of tying personnel training to a specific culture and challenges of their regional affiliates. This is specifically applicable to global companies that have a lot of affiliates or acquire assets across the globe. Regionalization in personnel training is a movement toward decentralizing corporate education. Regionalization is executed by moving certain activities, such as personnel training, from a centralized location to the countries and regions where a company's international affiliates reside. In today's distributed environment, the future of personnel training entails empowering regional affiliates with such important activities as decision making, developing a regional or country strategy and its execution as they pertain to personnel training. These changes are likely to precipitate the need for such important new roles in per- 


\title{
Управление в социально-экономических системах
}

sonnel training as, say, a regional training architect or a country training analyst. These roles will be accountable for the forecasting of the affiliates' training needs and creating the appropriate environment for training execution. Moreover, the training content and its delivery, planning and logistics will become a responsibility of a contractor in a specific region or country.

\section{Conclusion}

Currently, the personnel training field in the United States industry faces quite a few challenges. These challenges include:

- Inconsistent personnel training standards and employee qualifications across various companies and solution providers.

- Decreased levels of employee loyalty and a negative attitude toward their employers' current practices, such as outsourcing.

- Complexity and diversity of employee career aspirations and professional motivation.

- Geographical and cultural segmentation of employees in the same organization.

- Lack of qualified employees in corporate training departments and the need to delegate the training tasks to other departments.

The field of personnel training, however, actively adapts to the new environment. In the US industry, the personnel training area successfully manages these challenges by:

- Changing the roles and accountability of both the training professionals and the students.

- Changing approaches to personnel training.

- Adopting the practices used by other corporate areas that influence human behaviors, such as Organizational Change Management and partnering up with these areas.

The analysis of the current trends in personnel training allows us to forecast the future trends in that field. In the near future, personnel training will focus on aligning the training with specific initiatives, ensuring employee accessibility to the latest knowledge and skills, guaranteeing the training remains attuned to the latest industry needs, and improving the alignment between the training and a specific culture.

\section{References}

1. Pinchot, Gifford III. An Alternative to Hierarchy. Leader to Leader. Vol. 1998, Iss. 10, P. 41-46, Autumn (Fall), 1998.

Received 7 August 2016

удк 331.108

DOI: $10.14529 /$ ctcr160409

\section{СОВРЕМЕННЫЕ ТЕНДЕНЦИИ В ОБУЧЕНИИ ПЕРСОНАЛА ОРГАНИЗАЦИЙ И ПРЕДПРИЯТИЙ В США}

\author{
М. Стуль' ${ }^{1}$, А.P. Чапцов ${ }^{2}$ \\ ${ }^{1}$ Conducive Corp., Чикаго, umam Иллинойс, США, \\ ${ }^{2}$ Институт организационного и личного развития «Эго ресурс», г. Челябинск, \\ Российская Федерация
}

Цель этой статьи - познакомить читателей с современными тенденциями тренировки персонала. Статья освещает направления развития обучения сотрудников предприятий и организаций в Соединенных Штатах Америки.

Перед современным корпоративным обучением в США стоит немало вызовов. Для того, чтобы выжить в новых условиях, область обучения персонала должна найти новые пути развития. Авторы размышляют над теми факторами, которые способствуют или препятствуют созданию благоприятных для обучения персонала условий. В статье рассматриваются мето- 
ды, которые корпоративная педагогика активно использует, чтобы не только успешно адаптироваться к новым условиям, но и помочь предприятиям и организациям в США сформировать сотрудника будущего.

В статье также рассматриваются перспективы развития корпоративной педагогики. Статья ориентирована на сотрудников отделов кадров российских предприятий и организаций, менеджеров отделов обучения персонала, а также владельцев бизнесов, заинтересованных в подготовке квалифицированных кадров.

Ключевые слова: тренировка персонала, корпоративная педагогика.

\section{Лumepamypa}

1. Pinchot, Gifford III. An Alternative to Hierarchy. Leader to Leader, Vol. 1998, Issue 10, pages 41-46, 1998.

Стуль Михаил, $\mathrm{PhD}$, специалист по обучению персонала, Conducive Corp., Чикаго, штат Иллинойс, США; mstulphd@gmail.com.

Чапцов Артем Рудольфович, консультант по организационному развитию. Образовательная автономная некоммерческая организация «Институт организационного и личного развития «Эго ресурс» (ОАНО Институт «Эго ресурс»), г. Челябинск.

Поступила в редакцию 7 августа 2016 г.

\section{ОБРАЗЕЦ ЦИТИРОВАНИЯ}

Stul, M. Current Trends in Personnel Training in the United States Industry / M. Stul, A. Chaptsov // Вестник ЮУрГУ. Серия «Компьютерные технологии, управление, радиоэлектроника». - 2016. - Т. 16, № 4. C. 83-93. DOI: $10.14529 /$ ctcr 160409

\section{FOR CITATION}

Stul M., Chaptsov A. Current Trends in Personnel Training in the United States Industry. Bulletin of the South Ural State University. Ser. Computer Technologies, Automatic Control, Radio Electronics, 2016, vol. 16, no. 4, pp. 83-93. DOI: $10.14529 /$ ctcr160409 